\title{
Bayesian analysis of hybridization and introgression between the endangered european mink (Mustela lutreola) and the polecat (Mustela putorius)
}

\author{
M. T. CABRIA, ${ }^{*}+$ J. R. MICHAUX,十‡ B. J. GÓMEZ-MOLINER, ${ }^{*}$ D. SKUMATOV,§ T. MARAN, ${ }^{* *}$ \\ P. FOURNIER, 什 J. LÓPEZ DE LUZURIAGA㧊 and R. ZARDOYA§§ \\ *Departamento de Zoología y B.C.A., Facultad de Farmacia, Universidad del País Vasco UPV-EHU, Paseo de las Universidades, \\ 7, 01006 Vitoria-Gasteiz, Spain, +Laboratoire de Génétique des Microorganismes, Institut de Botanique (Bat.22), Université de \\ Liège (Sart Tilman), Boulevard du Rectorat, 27, B4000 Liège, Belgium, ‡Centre de Biologie et de Gestion des Populations, \\ CBGP, Campus international de Baillarguet, CS 30016, 34988 Montferrier-sur-Lez Cedex, France, §Russian Research Institute \\ of Game Management and Fur Farming, Engels Street, 79, Kirov, Russia, -Species Conservation Lab, Tallinn Zoological \\ Gardens, Paldiski Road 145, Tallinn 13522, Estonia, **Institute of Mathematics and Natural Sciences, Tallinn University, Narva \\ Road 25, Tallinn 10120, Estonia, †+Groupe de Recherche et d'Etudes pour la Gestion de l'Environnement (GREGE), Route de \\ Préchac, 33730 Villandraut, France, 抽enida de Gasteiz, no. 91-70B, 01009 Vitoria-Gasteiz, Spain, §§Departamento de \\ Biodiversidad y Biología Evolutiva, Museo Nacional de Ciencias Naturales, CSIC, José Gutiérrez Abascal, 2, 28006 Madrid, \\ Spain
}

\begin{abstract}
Human-mediated global change will probably increase the rates of natural hybridization and genetic introgression between closely related species, and this will have major implications for conservation of the taxa involved. In this study, we analyse both mitochondrial and nuclear data to characterize ongoing hybridization and genetic introgression between two sympatric sister species of mustelids, the endangered European mink (Mustela lutreola) and the more abundant polecat (M. putorius). A total of 317 European mink, 114 polecats and 15 putative hybrid individuals were collected from different localities in Europe and genotyped with $\mathbf{1 3}$ microsatellite nuclear markers. Recently developed Bayesian methods for assigning individuals to populations and identifying admixture proportions were applied to the genetic data. To identify the direction of hybridization, we additionally sequenced mtDNA and Y chromosomes from 78 individuals and 29 males respectively. We found that both hybridization and genetic introgression occurred at low levels ( $3 \%$ and $0.9 \%$ respectively) and indicated that hybridization is asymmetric, as only pure polecat males mate with pure European mink females. Furthermore, backcrossing and genetic introgression was detected only from female first-generation (F1) hybrids of European mink to polecats. This latter result implies that Haldane's rule may apply. Our results suggest that hybridization and genetic introgression between the two species should be considered a rather uncommon event. However, the current low densities of European mink might be changing this trend.
\end{abstract}

Keywords: Bayesian methods, hybridization, introgression, microsatellites, mtDNA, Y chromosome

Received 12 April 2010; revision received 5 November 2010; accepted 23 November 2010

Correspondence: Maria Teresa Cabria, Fax: (+34) 945013014; (+32) 43663847; E-mail: maitec79@yahoo.es

\section{Introduction}

Hybridization is defined as the mating between individuals of genetically different taxa showing incomplete reproductive barriers (Allendorf et al. 2001). 
Traditionally, it was assumed that hybridization in animals would play a small role in species diversification as it was thought to be a rather uncommon event (Dowling \& Secor 1997) that would normally lead to unviable or infertile F1 individuals. However, many recent genetic analyses show that hybridization in animals is more frequent than previously thought (Pastorini et al. 2009) and may have important evolutionary consequences (Arnold 1992; Barton 2001). Although it may occur naturally, ongoing human-mediated global change processes such as habitat fragmentation or species introduction are enhancing considerably animal hybridization events (Rhymer \& Simberloff 1996; Allendorf \& Luikart 2007; Kingston \& Gwilliam 2007). Among the evolutionary outcomes of hybridization, the most relevant one is genetic introgression, i.e. the backcross of genetic material by first-generation hybrids into one or both parental species (Arnold 1992; Rhymer \& Simberloff 1996). Introgression may play a creative evolutionary role through acquisition of higher fitness and competitive adaptive advantage of introgressed genotypes, as occurs in many plants. However, introgression may also have negative consequences if the loss of distinct gene pools due to the merging of both parental species leads to outbreeding depression (i.e. less fit introgressed genotypes) or if there is biased gene flow into one parental species due to a predominant direction of interspecific mating (Arnold 1992; Rhymer \& Simberloff 1996; Allendorf \& Luikart 2007). Introgression can be particularly problematic for endangered species coming into contact with more abundant ones in a humanmediated global change context (Allendorf \& Luikart 2007; Kingston \& Gwilliam 2007). In the worst-case scenario, outbreeding depression may have dramatic consequences, which could lead to rapid extinction of the endangered species, and thus there is great debate regarding whether implementing management actions (e.g., eliminating hybrid individuals or expanding pure individuals into the wild) is appropriate in such cases (Rhymer \& Simberloff 1996; Allendorf et al. 2001; Frankham et al. 2002). Although the efficiency and type of existing reproductive isolation barriers seem to be determinant in shaping hybridization (Coyne \& Allen Orr 2004), the relative incidence and nature of the process do not follow a common pattern among different organisms. More ecological and genetic studies in different species are needed to characterize hybridization in the wild, both under natural conditions and under anthropogenic disturbance, in order to understand the evolutionary consequences of the process, and to implement appropriate conservation actions when needed.

Hybridization is documented as a rather common event in the mammalian order Carnivora. For example, it has been detected in wild animals between red wolfs
(Canis rufus) and coyotes (Canis latrans) in the United States (Adams et al. 2007), and between different genet species (Geneta spp.) in southern Africa (Gaubert et al. 2005). In some other cases, domestic relatives are involved in the process, for instance between wild and domestic cats (Felis silvestris) in Scotland (Beaumont et al. 2001) and Portugal (Oliveira et al. 2008), or between wolfs (Canis lupus) and dogs (Canis familiaris) in Scandinavia (Vila et al. 2003). In particular, it has been described in mustelids between the endangered European mink (Mustela lutreola L., 1761) and the more abundant polecat (Mustela putorius L., 1758), two sister species that show incomplete reproductive barriers (e.g. Birks 1995; Lynch 1995; Davison et al. 1999). The European mink is considered one of the most threatened carnivores in Europe. It is assigned to the endangered category (2008 IUCN Red List; http://www.iucnredlist.org) due to its severe decline over the last century (Maran et al. 1998). Surviving populations are restricted to riparian habitats in three isolated areas: western (southwestern France and northern Spain), northeastern (Estonia, Belarus and Russia) and southeastern (Romania) Europe (Maran \& Henttonen 1995). The main factors currently threatening European mink populations are habitat loss, pollution and hunting, as well as the impact of the American mink Neovison vison due to intra-guild aggression, introduced diseases, food competition and hybridization (Maran 2007). The polecat is assigned to the category of least concern (2008 IUCN Red List; http://www.iucnredlist.org) because of its large population sizes and wide distribution throughout Europe (Fernandes et al. 2008). However, its populations are currently decreasing in some parts of Europe due to the scarcity of prey, habitat change and hunting (Pertoldi et al. 2006; Fernandes et al. 2008). These two sister species with completely different conservation status and population dynamics may be considered as a particularly useful model system to study the evolutionary and conservation consequences of hybridization and genetic introgression when these are forced by human-mediated pressure.

Sidorovich (2001) studied the frequency and ecological features of hybrid individuals between both species, and reviewed the morphological traits that allow identification of the hybrid intermediate phenotype. Colour pattern and body size were considered the main distinctive features for hybrid detection. It was reported that hybrids have distinct phenotypic characters, such as dorsal pelage, mask, underhair, guardhair and ears, which are intermediate to those exhibited by the parental species (Davison et al. 2000b; Sidorovich 2001). However, the mixture of morphological characters is sometimes ambiguous because hybrids can express a great variety of possible parental phenotypes. In such 
cases, correct hybrid detection may be seriously hindered and hybridization rates may be underestimated (Rhymer \& Simberloff 1996; Allendorf et al. 2001; Gow et al. 2006). Furthermore, phenotypic characters fail to determine whether hybrids belong to backcross, first or successive generations (Allendorf et al. 2001).

The application of genetic markers provides many advantages over the use of phenotypic characters in characterizing hybridization and introgression, and is particularly helpful for conservation purposes when it exposes cryptic hybridization phenomena that could jeopardize the genetic integrity and preservation of threatened species (Rhymer \& Simberloff 1996; Allendorf et al. 2001). Identification of hybrids between native Westslope cutthroat trout (Oncorhynchus clarki lewisi) and introduced rainbow trout (Oncorhynchus mykiss) in the United States and Canada using at least five diagnostic loci provided a $95 \%$ probability of detecting as little as $1 \%$ admixture in a hybrid population and were particularly helpful in determining backcrosses (Allendorf et al. 2004). Moreover, molecular analyses revealed complex hybridization dynamics and extensive cryptic introgression in golden-winged warblers, seriously threatened by blue-winged warblers (Vermivora pinus), supporting that previous hybrid assessments based on phenotypic traits were highly underestimated (Vallender et al. 2007). In the case of southern African genets, mitochondrial cytochrome $b$ gene rendered successful results in detecting extensive cryptic hybridization between Genetta tigrina and Genetta felina (Gaubert et al. 2005).
For European mink and polecats, the only available molecular study investigated allozyme and microsatellite variation of the two mustelid species in France to identify species-diagnostic alleles, and to determine the effective hybridization rate (Lodé et al. 2005). Of the 51 European mink and 126 polecat individuals tested, only one individual was identified as a hybrid. Although the applied molecular markers rendered valuable results for hybrid detection, several key questions such as direction of hybridization, hybrid classification and level of introgression in the wild populations were not addressed and remain unknown. Moreover, the study was restricted to France and the dynamics of hybridisation in other parts of the species range remain unquantified.

In this study, samples of European mink and polecat were collected from populations throughout Europe (western, central, northeastern and southeastern Europe; see Fig. 1). Biparentally inherited nuclear markers (microsatellites) were analysed to identify parentals and hybrids, as well as to classify the latter into different hybrid categories (F1, F2 or backcrosses). Furthermore, we identified species-specific mitochondrial DNA (mtDNA; maternally inherited) and $\mathrm{Y}$ chromosome (paternally transmitted) haplotypes of European mink and polecat respectively, in order to determine the direction of hybridization. Altogether, the newly obtained genetic data were analysed in an evolutionary context to provide new insights on the frequency of hybridization between the two species, hybrid proportions in the different regions, the possible existence of

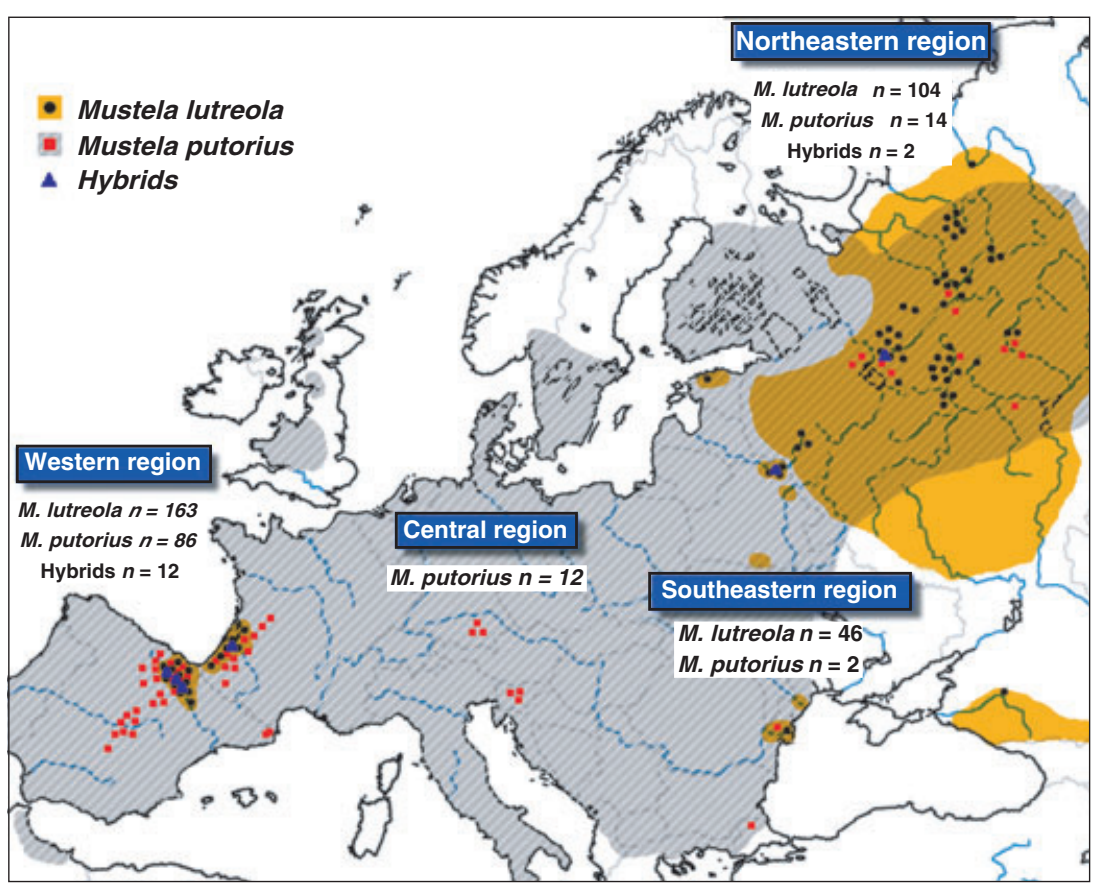

Fig. 1 Distribution and sampling localities of the European mink (orange area and black dots respectively) and polecat (grey area and red squares respectively). The extant population of European mink in regions of north-eastern Europe is restricted to isolated patches. Hybrid samples are highlighted with blue triangles. There are no geographic coordinates associated to the Russian hybrid. Hence, its location in the figure is only approximate. Sampled individuals of each parental species and confirmed hybrids are given per region. Distribution range of the European mink has been drawn according to Maran (2007) and de Jong et al. (2007). The distribution range of polecats has been drawn according to the IUCN. 
reproductive isolating barriers, as well as the viability, fertility and differential fitness of F1 hybrids. Moreover, we investigated the potential role of hybridization in the decline of the threatened European mink.

\section{Material and methods}

\section{Sample collection and DNA extraction}

Phenotypic characteristics were used as prior information for species identification to assign individuals to one of the pure species (M. lutreola or M. putorius) or as a putative hybrid before genetic analyses. Samples were collected in up to four different European regions: Northeast, Southeast, Central and West (Fig. 1): European mink ( $n=317$; Ind $1-317)$ were sampled in northeastern (Russia, Belarus and Estonia; $n=104$ ), southeastern (Romania; $n=46$ ) and western (France and Spain; $n=163)$ regions; polecats $(n=114$; Ind 318-431) were collected from northeastern (Russia; $n=14$ ), southeastern (Romania and Turkey; $n=2$ ), central (Germany and Slovenia; $n=12$ ) and western (France and Spain; $n=86)$ regions; and putative hybrids ( $n=15$; Ind $432-$ 446) were sampled in northeastern (Russia and Belarus; $n=4$ ) and western (Spain; $n=11$ ) Europe (Fig. 1).

Genomic DNA was isolated from muscle, liver or hair samples, which were stored individually in 96\% ethanol and frozen at $-20^{\circ} \mathrm{C}$ prior to laboratory analysis.

\section{Microsatellite genotyping}

All 446 sampled individuals were genotyped using 13 microsatellite loci. Of these, six microsatellites (MLUT04, MLUT20, MLUT25, MLUT27, MLUT 32 and MLUT35) were isolated from the European mink (Cabria et al. 2007), whereas the remaining were originally developed for either the American mink, N. vison (MVIS22, MVIS72, MVIS75 and MVIS99) or the stoat, Mustela erminea (MER09, MER22 and MER41) (Fleming et al. 1999).

Polymerase chain reaction (PCR) amplifications for microsatellite markers MLUT27, MLUT32, MLUT35, MVIS22, MVIS72, MVIS75, MVIS99, MER09, MER22 and MER41 were performed using the QIAGEN ${ }^{\circledR}$ Multiplex PCR Kit according to the manufacturer's protocol at optimized annealing temperatures. PCR reactions contained $10-15 \mathrm{ng}$ of genomic DNA, $0.12-0.3 \mu \mathrm{M}$ of primers and $5 \mu \mathrm{L}$ of PCR Master Mix. PCR conditions consisted of an initial HotStart Taq DNA Polymerase activation step of $15 \mathrm{~min}$ at $95^{\circ} \mathrm{C}$, followed by 35 cycles of denaturing at $95^{\circ} \mathrm{C}$ for $30 \mathrm{~s}$, annealing at $57-60{ }^{\circ} \mathrm{C}$ for $90 \mathrm{~s}$ and extension at $72{ }^{\circ} \mathrm{C}$ for $60 \mathrm{~s}$, with a final extension step at $72{ }^{\circ} \mathrm{C}$ for $30 \mathrm{~min}$. Microsatellites MLUT04, MLUT20 and MLUT25 were amplified indi- vidually using the following PCR mixture: 10-20 ng of genomic DNA, 0.1-0.2 $\mu \mathrm{M}$ of each primer, $0.3 \mathrm{~mm}$ dNTPs, $1.06-1.5 \mathrm{~mm} \mathrm{MgCl}_{2}, 0.04-0.06 \mathrm{mg} / \mathrm{mL}$ of BSA, $1 \times$ reaction buffer and 0.45 units of Bio Taq DNA polymerase (Bioline). PCR conditions consisted of an initial denaturing step at $94{ }^{\circ} \mathrm{C}$ for $5 \mathrm{~min}$, followed by 35 cycles of denaturing at $94{ }^{\circ} \mathrm{C}$ for $30 \mathrm{~s}$, annealing at 52-57 ${ }^{\circ} \mathrm{C}$ for $45 \mathrm{~s}$ and extension at $72{ }^{\circ} \mathrm{C}$ for $45 \mathrm{~s}$, with a final extension step at $72{ }^{\circ} \mathrm{C}$ for $20 \mathrm{~min}$.

PCR products were run and analysed with an $\mathrm{ABI}$ PRISM 3730 automated sequencer (Applied Biosystems). Microsatellite allele sizes were scored with GeneScan $^{\mathrm{TM}}$ 500LIZ ${ }^{\circledR}$ Size Standard using GeneMapper v. 3.7 (Applied Biosystems).

\section{Sequencing of mtDNA}

The mtDNA control region was selected for this study because it provided adequate levels of genetic variation at the population level in previous studies focused on mustelids (Gómez-Moliner et al. 2004; Michaux et al. 2004, 2005; Pertoldi et al. 2006). A fragment of 614-bp of the mtDNA control region was amplified in European mink and polecats, using two PCR primers: LutbF (5'-AGAACACCCATTCATCATTATCG-3'; Pertoldi et al. 2006) and MLDloopR (5'-AGTCATTAGTCCATCGA GATGTC-3'; this study). PCR reactions contained 10-20 $\mathrm{ng}$ of genomic DNA, $0.26 \mu \mathrm{M}$ of each primer, $1.13 \mathrm{~mm}$ of each dNTP, $0.84 \mathrm{~mm} \mathrm{MgCl} 2,1 \times$ reaction buffer and 0.45 units of Bio Taq DNA polymerase (Bioline). PCR amplifications consisted of an initial denaturing step at $94{ }^{\circ} \mathrm{C}$ for $5 \mathrm{~min}, 35$ cycles of denaturing at $94{ }^{\circ} \mathrm{C}$ for $50 \mathrm{~s}$, annealing at $58{ }^{\circ} \mathrm{C}$ for $45 \mathrm{~s}$ and extension at $72{ }^{\circ} \mathrm{C}$ for $90 \mathrm{~s}$, and a final extension step of $72{ }^{\circ} \mathrm{C}$ for $10 \mathrm{~min}$. PCR products were purified using the QIAquick PCR Purification Kit $\left(\right.$ QIAGEN $\left.^{\circledR}\right)$ and sequenced on ABI PRISM 3700 and 3730 (Applied Biosystems) automated sequencers using the BigDye Terminator Cycle Sequencing Ready Reaction Kit (Applied Biosystems) and following manufacturer's instructions.

We analysed sequence variation in the mtDNA control region of 78 samples (European mink; $n=19$, polecats; $n=44$, and putative hybrids; $n=15$; Appendix S1, Supporting information). The mtDNA sequences of European mink were obtained from a complementary study on European mink phylogeography (MT Cabria, EG Gonzalez, BJ Gomez-Moliner, R Zardoya, unpublished data) and represent 17 mtDNA haplotypes (EU548035-EU548051). Similarly, we retrieved 24 mtDNA haplotype sequences of polecat available in GenBank (AY962022-AY962045; Pertoldi et al. 2006). These sequences are about $2000 \mathrm{bp}$ in length and include our 614-bp fragment. They corresponded to samples of central (Belgium, Denmark and Poland) and 
southwestern (Spain) Europe. We sequenced an additional 20 polecat individuals, mostly from central and eastern Europe to provide representative geographic coverage of the species throughout Europe. We used the mtDNA control region sequences of the following three species as outgroups: the otter, Lutra lutra, which was retrieved from GenBank (NC011358.1), the American mink, N. vison (FJ589735) and the Siberian weasel, Mustela sibirica (FJ589734), which were sequenced anew for this study.

\section{Sequencing of Y chromosome}

Partial sequences of introns 5 and 7 of the Dead Box polypeptide 3 Y-linked (DDX3Y or DBY) gene (Hellborg \& Ellegren 2003) were determined in order to find species-specific nucleotides that allow for the identification of the paternal origin of individuals. PCR amplifications were conducted in a final volume of $15 \mu \mathrm{L}$ containing $0.53 \mu \mathrm{m}$ of each primer, $1.33 \mathrm{~mm}$ dNTPs, $2 \mathrm{~mm} \mathrm{MgCl}_{2}$, $1 \times$ reaction buffer, $0.13 \mathrm{mg} / \mathrm{mL}$ BSA, 0.5 units of Bio Taq DNA polymerase (Bioline) and approximately 10-20 ng of template DNA. PCR conditions consisted of an initial denaturing step at $94{ }^{\circ} \mathrm{C}$ for $5 \mathrm{~min}$, followed by 35 cycles of denaturing at $94{ }^{\circ} \mathrm{C}$ for $50 \mathrm{~s}$, annealing at $50{ }^{\circ} \mathrm{C}$ for $50 \mathrm{~s}$ and extension at $72{ }^{\circ} \mathrm{C}$ for $90 \mathrm{~s}$, with a final extension step at $72{ }^{\circ} \mathrm{C}$ for $10 \mathrm{~min}$. PCR products were purified using the QIAquick PCR Purification Kit $\left(\right.$ QIAGEN $\left.^{\circledR}\right)$, and sequenced in automated DNA sequencers (ABI PRISM 3700 and 3730) using the BigDye Terminator Cycle Sequencing Kit (Applied Biosystems), following manufacturer's instructions.

The DDX3Y introns 5 (DDX3Y5) and 7 (DDX3Y7) were sequenced in seven male European mink (Russia; $n=5$, Belarus; $n=1$, Spain; $n=1$ ), and 12 male polecats (Russia; $n=4$, Romania; $n=1$, Slovenia; $n=1$, France; $n=2$, Spain; $n=4$ ) (Appendix S1, Supporting information). The DDX3Y7 data set showed no variation in the nucleotide sequence between the two mustelid species. Thus, it was discarded for determining the paternal origin of the samples. The DDX3Y5 was amplified in 10 putative male hybrids (Russia; $n=2$, Belarus; $n=1$, Spain; $n=7$; Appendix S1, Supporting information).

\section{Microsatellite genetic analyses}

The Gimlet program version 1.3.3 (Valiere 2002) was used to identify and correct genotyping errors. Number of alleles per locus $\left(N_{\mathrm{A}}\right)$, number of private alleles $\left(P_{\mathrm{A}}\right)$, allelic richness $\left(A_{\mathrm{R}}\right)$, observed $\left(H_{\mathrm{O}}\right)$ and expected $\left(H_{\mathrm{E}}\right)$ heterozygosities, as well as the inbreeding coefficient $\left(F_{\mathrm{IS}}\right)$, were calculated per microsatellite locus and sampling site for both European mink and polecat using GENETIX version 4.05 (Belkhir et al. 2000) and FSTAT ver- sion 2.93 (Goudet 1995). Genetic differentiation was estimated with the $F_{\mathrm{ST}}$ statistic (Weir \& Cockerham 1984) using ARLEQUIN v. 3.0 (Excoffier et al. 2005). Significance levels were assessed by conducting 10000 permutations. Deviations from Hardy-Weinberg (HW) equilibrium were tested using the exact test implemented in GENEPOP version 3.3 (Raymond \& Rousset 1995). Significance was evaluated by running a Markov-Chain Monte-Carlo (MCMC) consisting of 10000 batches of 10000 iterations each, with the first 10000 iterations discarded before sampling (Guo \& Thompson 1992). Significance levels were adjusted with sequential Bonferroni correction in order to correct for the effect of multiple tests (Rice 1989).

Patterns of genetic differentiation were visualized with a Factorial Correspondence Analysis (FCA) using GENETIX program v. 4.02 (Belkhir et al. 2000). Multiple variables (allele frequencies at different loci) were used to compute a linear relationship that best explains the variation between individuals.

Biparental multilocus genotypes were analysed using two different Bayesian approaches to estimate admixture proportions and to assign individuals to populations:

1 Structure version 2.2 (Pritchard et al. 2000; Falush et al. 2003, 2007) was used to determine the level of admixture, calculated as the proportion of the genome of an individual that is derived from each of the two parental species. Simulations were run using a burn-in period of $10^{5}$ sweeps followed by $10^{6} \mathrm{MCMC}$ iterations. Independent runs of $\mathrm{K}$ (i.e. number of clusters or gene pools assumed) were performed from one to five clusters and repeated 10 times to check for consistency of results. Admixture ancestry and correlated allele frequency models were used without prior knowledge of genetic information. Individual assignment probabilities refer to the proportion of an individual's genome derived from European mink $\left(q_{i}\right)$ or polecats $\left(q_{j}\right)$.

2 A second Bayesian model-based clustering method for identifying hybrids was perform with NEWHYBRIDS version 1.1 beta (Anderson \& Thompson 2002). The method identifies hybrid individuals on the basis of the posterior probability $(Q)$ of belonging to different pure parental or hybrid categories generated during $n=2$ or $n=3$ generations of potential interbreeding. Six distinct genotype frequency classes were defined: pure species I, pure species II, F1 hybrids, F2 hybrids and backcrosses with pure species I (BxI) and with pure species II (BxII). Simulations were run with $10^{6}$ sweeps for the burn-in period and $10^{6}$ MCMC iterations. The Jeffreys-like and the Uniform priors were assumed for $\theta$ (allele frequencies) and $\pi$ (mixing proportions) in order to verify the congruence of the 
results. Individuals living in allopatric areas can be considered pure, and this genetic information can be incorporated as extra prior information into the analyses. Hence, computations were executed with and without prior information on individual's genotype frequency category and allele frequency of polecats from allopatric areas (European mink typically occurs sympatrically with polecats).

The clusters obtained with both Bayesian statistical methods were displayed in a graphical plot using the program DISTRUCT version 1.1 (Rosenberg 2004). Following Kaeuffer et al. (2007), the correlation coefficient rLD was estimated before running Bayesian clustering analyses to evaluate its influence on the clustering estimation, as well as to avoid the clustering bias generated by the presence of high rLD values. The rLD between all pairs of loci was calculated using the GENETIX software (Belkhir et al. 2000) and did not show significant association between pairs of loci (data not shown).

The HYBRIDLAB program (Nielsen et al. 2006) was used to assess the power of Bayesian approaches and to evaluate whether these methods could accurately identify admixture and classify hybrids. The program generates multilocus simulated genotypes by randomly sampling alleles from two populations assuming random mating, linkage equilibrium and neutrality. In this case, HYBRIDLAB was used to generate a simulated data set of each parental and hybrid class using genotypes from M. lutreola and M. putorius with $q_{i}$ and $q_{j}$ thresholds above 0.98. A total of 100 simulated genotypes were generated per each parental and hybrid class, and the procedure was repeated 10 times. The simulated data sets were then evaluated using STRUCTURE in a similar manner to the empirical data in order to estimate the threshold value for individual assignment. No prior information was used for simulated genotypes. The analysis performed showed a threshold of $q_{i}$ and $q_{j}$ of 0.861 (minimum $q$-value of simulated parental genotypes). Setting the threshold $q$-value at 0.861 , the efficiency (i.e. the proportion of individuals in a group that were correctly identified; Vähä \& Primmer 2006) was $97 \%$. The other $3 \%$ corresponded to simulated genotypes of backcross hybrids, which showed $q$-values higher than 0.861 as expected for parental genotypes. Therefore, to increase the power of our analyses and reduce percentage error, we set a more conservative threshold $q$-value at 0.95 rendering an efficiency of hybrid identification of $99.99 \%$.

\section{Mitochondrial DNA and Y chromosome genetic analyses}

Paternal and maternal origins were detected by direct nucleotide comparison of European mink and polecat
mtDNA and DDX3Y5 sequences. The mtDNA sequences were aligned using the default parameters of CLUSTAL_X version 1.83 (Thompson et al. 1997). Alignments were subsequently revised by eye. Gapped positions were excluded from the data set. Nucleotide $(\pi)$ and haplotype $(h)$ diversities were estimated using ARLEQUIN version 3.1 (Schneider et al. 2000). Phylogenetic trees were reconstructed using Bayesian inference (BI; Huelsenbeck et al. 2001) with MrBayes v 3.0b4 (Huelsenbeck \& Ronquist 2001; Ronquist \& Huelsenbeck 2003). GTR was selected as the best-fit evolutionary model for the data set according to the Akaike Information Criterion as implemented in ModelTest version 3.6 (Posada \& Crandall 1998). BI was performed with four simultaneous chains, each of $10^{6}$ generations, sampled every 100 generations (the first 1000 trees were discarded as 'burn-in').

The DDX3Y5 data set produced an alignment of 429 positions, and $\mathrm{Y}$ chromosome sequences of European mink and polecat showed three distinct species-specific nucleotides that differentiated two haplotypes: MlhDDX3Y5 (GenBank accession number FJ556592), which was found exclusively in European mink individuals, and Mph-DDX3Y5 (FJ556591), which was fixed in polecats. The paternal origin of the hybrids was assigned to one or the other parental species based on these two haplotypes.

\section{Results}

\section{Genetic diversity at microsatellite loci and species identification}

All but two of the analysed microsatellite loci were polymorphic in both mustelid species, and rendered a total of 67 (ranging from 2 to 10) and 74 (ranging from 2 to 11) alleles in European mink and polecat respectively (Table 1; see also Appendix S2, Supporting information). Only loci MLUT27 and MVIS99 were monomorphic in European mink. Comparison of $H_{\mathrm{E}}$ and $H_{\mathrm{O}}$ revealed slight differences between European mink and polecat (Table 1). Observed heterozygosity was lower than expected heterozygosity in both species. Inbreeding coefficients were positive at all loci in European mink whereas negative $F_{\text {IS }}$ values were found at loci MLUT35, MVIS75 and MVIS99 within polecat, suggesting an excess of heterozygotes (Table 1). Significant departure from HW equilibrium after Bonferroni correction was observed at four loci in European mink populations, whereas only one locus deviated from HW equilibrium proportions in polecat populations. The program FreeNA (Chapuis \& Estoup 2007) was applied to test the presence of null alleles in the microsatellite data set. The results rejected the hypothesis of putative 
1182 M. T. CABRIA ET AL.

Table 1 Summary of the genetic variability assessed per loci and species

\begin{tabular}{|c|c|c|c|c|c|c|c|c|c|c|c|c|}
\hline \multirow[b]{2}{*}{ Locus } & \multicolumn{6}{|c|}{ Mustela lutreola } & \multicolumn{6}{|c|}{ Mustela putorius } \\
\hline & $N_{\mathrm{A}}$ & $P_{\mathrm{A}}$ & $A_{\mathrm{R}}$ & $H_{\mathrm{O}}$ & $H_{\mathrm{E}}$ & $F_{\mathrm{IS}}$ & $N_{\mathrm{A}}$ & $P_{\mathrm{A}}$ & $A_{\mathrm{R}}$ & $H_{\mathrm{O}}$ & $H_{\mathrm{E}}$ & $F_{\text {IS }}$ \\
\hline MLUT04 & 4 & 4 & 4.000 & 0.3311 & 0.4534 & 0.270 & 3 & 2 & 3.000 & 0.1584 & 0.2278 & 0.306 \\
\hline MLUT20 & 9 & 5 & 8.070 & 0.4984 & 0.7389 & 0.326 & 6 & 3 & 5.909 & 0.4775 & 0.6794 & 0.298 \\
\hline MLUT25 & 6 & 3 & 4.875 & 0.5064 & 0.6265 & 0.192 & 5 & 3 & 4.902 & 0.4865 & 0.6507 & 0.253 \\
\hline MLUT27 & 1 & - & 1.000 & - & - & - & 3 & 2 & 2.992 & 0.0991 & 0.1276 & 0.224 \\
\hline MLUT32 & 10 & 2 & 8.937 & 0.5641 & 0.6987 & 0.193 & 11 & 2 & 10.616 & 0.2523 & 0.2866 & 0.120 \\
\hline MLUT35 & 4 & 1 & 3.987 & 0.2300 & 0.2799 & 0.178 & 2 & - & 2.000 & 0.0364 & 0.0359 & -0.014 \\
\hline MER09 & 4 & 1 & 3.999 & 0.3962 & 0.5056 & 0.217 & 5 & - & 4.812 & 0.1351 & 0.1675 & 0.194 \\
\hline MER22 & 7 & 4 & 6.536 & 0.5279 & 0.6943 & 0.240 & 5 & 1 & 4.994 & 0.1273 & 0.1871 & 0.321 \\
\hline MER41 & 5 & 1 & 4.690 & 0.3387 & 0.5905 & 0.427 & 7 & 1 & 6.992 & 0.5946 & 0.6648 & 0.106 \\
\hline MVIS22 & 6 & 1 & 5.726 & 0.5590 & 0.7329 & 0.238 & 10 & 4 & 9.994 & 0.6273 & 0.8256 & 0.241 \\
\hline MVIS72 & 8 & 1 & 7.206 & 0.4286 & 0.6197 & 0.309 & 9 & - & 8.912 & 0.5636 & 0.7035 & 0.200 \\
\hline MVIS75 & 2 & - & 2.000 & 0.3163 & 0.4144 & 0.237 & 4 & - & 3.819 & 0.0450 & 0.0445 & -0.012 \\
\hline MVIS99 & 1 & - & 1.000 & - & - & - & 4 & 1 & 3.819 & 0.0450 & 0.0445 & -0.012 \\
\hline All & 67 & 23 & 4.771 & 0.3613 & 0.4888 & 0.261 & 74 & 20 & 5.597 & 0.2806 & 0.3573 & 0.215 \\
\hline
\end{tabular}

$N_{\mathrm{A}}$, number of alleles; $P_{\mathrm{A}}$, private alleles; $A_{\mathrm{R}}$, allelic richness; $H_{\mathrm{O}}$, observed heterozygosity; $H_{\mathrm{E}}$, expected heterozygosity; $F_{\mathrm{IS}}$, inbreeding coefficient; $P_{\mathrm{A}}$, private allele $(P \geq>0.05)$.

null alleles causing bias in genetic diversity and population differentiation estimates.

Presence of private alleles, as well as differences in allele frequency distribution, are considered the most significant population or species distinction parameters in order to test genetic introgression (Beaumont et al. 2001; Oliveira et al. 2008). A total of 23 (34.33\%) and 20 $(27.03 \%)$ private alleles were found in European mink and polecat respectively (Table 1; see Appendix S2, Supporting information). A threshold frequency of 0.05 was considered to avoid sampling and/or genotyping errors. Interestingly, microsatellite loci MLUT04 and MLUT25 were species-specific with European mink alleles being 5 to $10 \mathrm{bp}$ larger in size (data not shown). On the other hand, most alleles shared by the two mustelid species showed differences in allele frequency distribution between species (Appendix S2, Supporting information).
Strong genetic differentiation was detected between the two mustelid species based on 13 microsatellite data $\left(F_{\mathrm{ST}}=0.531 ; P<0.001\right)$. In agreement with this result, a FCA separated individual microsatellite genotypes into two well-defined groups (Fig. 2). Moreover, FCA revealed internal genetic structure within European mink. A third group, which occupied an intermediate position between European mink and polecat groups, included eight putative hybrids (Ind 438-441 and Ind 443-446) as well as two samples that had been described as European mink (Ind 1) and polecat (Ind 318) based on phenotypic characters. Analyses of the hybrid genotypes of this group performed with NEWHYBRIDS program classified all of them into firstgeneration (F1) hybrid type (see below). Both Ind 319 and Ind 320, which had been described as polecats based on phenotypic characters, and putative hybrids Ind 437 and Ind 442 were placed on an intermediate

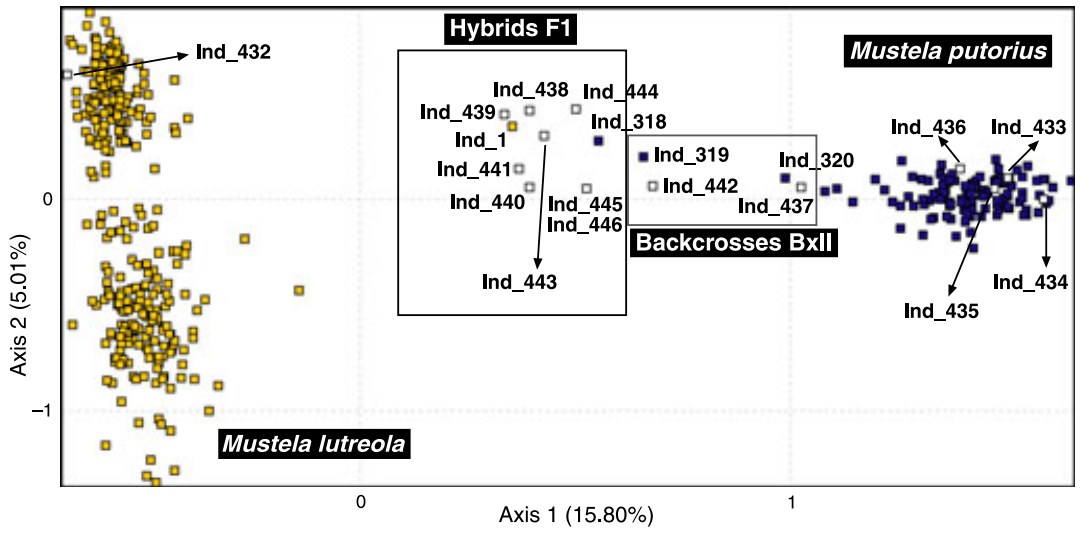

Fig. 2 Two-dimensional factorial correspondence analysis. Strong differentiation among European mink (yellow/ light-grey squares) and polecats (blue/ dark-grey squares) at nuclear loci was observed. Putative hybrids (white squares), localized at an intermediate position, were classified into hybrid categories F1 or BxII (backcross with polecat) using the Bayesian model-based clustering method as implemented in NEWHYBRIDS program (see Table 2 and Fig. 3 for further information). 
position partially overlapping with pure polecat individuals (Fig. 2). These four samples were assigned to backcross genotypic class BxII (backcross with polecat) with NEWHYBRIDS (see below). The putative hybrids Ind 432 and Ind 433-436 were grouped together with European mink and polecats respectively. They were assigned to pure categories with NEWHYBRIDS (see below), suggesting that those individuals are pure specimens.

\section{Bayesian inference of population structure and hybrid species identification}

The two Bayesian clustering methods used in the study produced consistent results. Using both methods, a total of 14 hybrids (3\%) were detected (Table 2). Of these, four were backcrosses $(0.9 \%)$. A total of 12 of the 14 hybrids were found in the western region, and the remaining two were from Russia and Belarus respectively. All backcrosses were detected in Spain (Table 2). Analyses using STRUCTURE with both the admixture ancestry and correlated allele frequency models supported the existence of two distinct genetic clusters $(k=2)$ based on the log probability of the data (ln $[\operatorname{Pr}(X / K)])$ given the model. Moreover, the modal value of $\Delta K$ (Evanno et al. 2005) was $K=2$. Cluster I grouped together the majority of samples identified as European mink based on phenotype, with an estimated average proportion of membership $\left(Q_{\mathrm{I}}\right)$ higher than 0.95 (Fig. 3a). Cluster II included most of the individuals phenotypically identified as polecat with $Q_{\text {II }}>0.95$ (Fig. 3a). Ind 1, from the western European region and considered to be an European mink based on phenotypic features, was assigned to both clusters with intermediate $q$ values $\left(q_{i}\right.$ and $\left.q_{j}<0.60\right)$, as expected in a first (F1) generation hybrid (Table 2; Fig. 3a). Similarly, three samples (Ind 318-320), also from Western Europe and identified as polecat based on phenotype, showed assignment probabilities below $0.90 \quad\left(0.148<q_{i}\right.$ and $q_{j}<0.852$ ) indicative of admixed ancestry (Table 2; Fig. 3a). Most of the putative hybrids (Ind 437-446) were assigned to both clusters with $q$-values below 0.60 $\left(0.181<q_{i}\right.$ and $\left.q_{j}<0.852\right)$, confirming their admixed genome (Table 2; Fig. 3a). The other five putative hybrids were assigned either to cluster I (Ind 432) or cluster II (Ind 433-436), with $q_{i}>0.95$ and $q_{j}>0.95$ respectively, and thus could be considered as either pure European mink or polecat. Identical results were obtained when the STRUCTURE analysis was run without using the admixture ancestry and correlated allele frequency models.

The different Bayesian analyses performed with NEWHYBRIDS provided identical results and, thus, we show only those obtained with uniform prior. The anal- yses revealed strong posterior probabilities of belonging to each of the predefined genotype frequency categories. All but one individual phenotypically considered to be a pure European mink were assigned to parental species I (pure I; Table 2, Fig. 3b), with average posterior probabilities of 0.999 , ranging from 0.978 to 1 (data not shown). The only exception was Ind 1, which was placed within the F1 hybrid class with a posterior probability of 0.999 (Table 2, Fig. 3b). On the other hand, $97 \%$ of the individuals phenotypically considered to be pure polecats were assigned to parental species II (pure II), with posterior probabilities higher than 0.95 (Fig. 3b). Polecat Ind 318 was assigned to the F1 genotype class with a posterior probability of 0.997 , whereas polecat Ind 319 was classified into the BxII class with a posterior probability of 0.923 (Table 2, Fig. 3b). Furthermore, polecat Ind 320 was ambiguously assigned to pure species II and BxII genotype classes with posterior probabilities of 0.485 and 0.513 respectively (Table 2, Fig. 3b).

Putative hybrids (Ind 432-446) were classified into different genotype frequency classes, with high posterior probabilities ranging from 0.922 to 1 (Table 2). Ind 432 was listed as belonging to pure I class, whereas Ind $433-436$ were classified as belonging to pure II class (Table 2, Fig. 3b). The remaining 10 putative hybrids were confirmed to have admixed genotypes. Ind 437 and Ind 442 were assigned to genotype frequency class BxII, whereas Ind 438-441 and Ind 443446 were classified as first-generation hybrids (Table 2, Fig. 3b).

The different analyses performed using the 'Jeffreyslike' prior yielded identical results except in the case of backcross individuals (Ind 319, Ind 320, Ind 437 and Ind 442), which were assigned with posterior probabilities higher than 0.96 to the BxII class (not shown). According to this result, these specimens could be backcrosses originated from matings between pure polecats and F1 hybrids.

\section{Mitochondrial DNA sequence diversity and identification of maternal origin}

A total of $81 \mathrm{mtDNA}$ nucleotide sequences (including European mink, polecats, putative hybrids and three outgroups) were merged into a single data set that produced an alignment of 491 positions after gap removal. Phylogenetic analysis recovered two main clades with high statistical support (BPPs $\geq 90 \%$ ) that corresponded to European mink (clade I) and polecat (clade II) (Fig. 4). Sequences of both species were distinguished by five specific nucleotide differences. The mtDNA sequence variability of European mink and polecats was defined by relatively low values of $\pi, 0.0062$ 
1184 M. T. CABRIA ET AL.

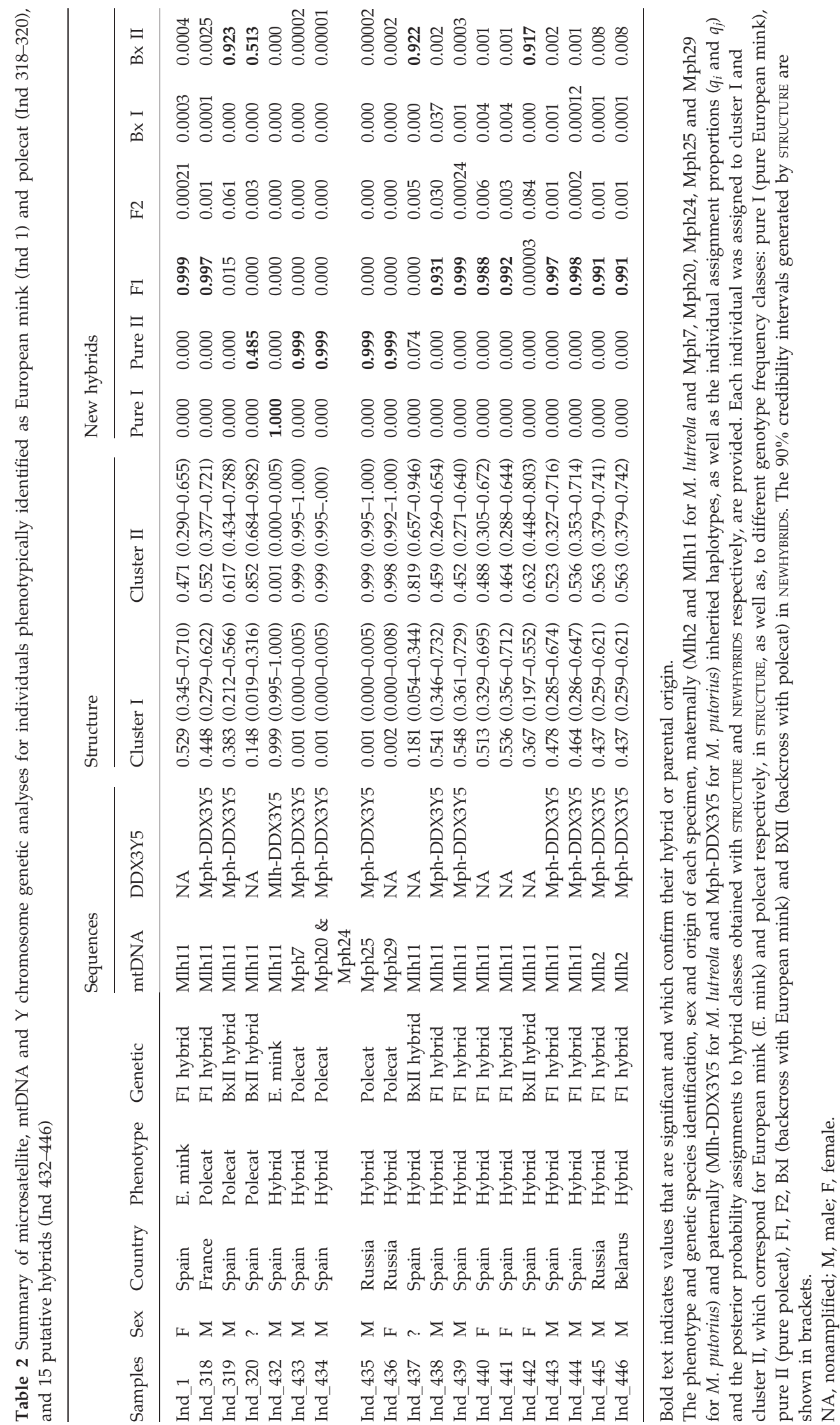



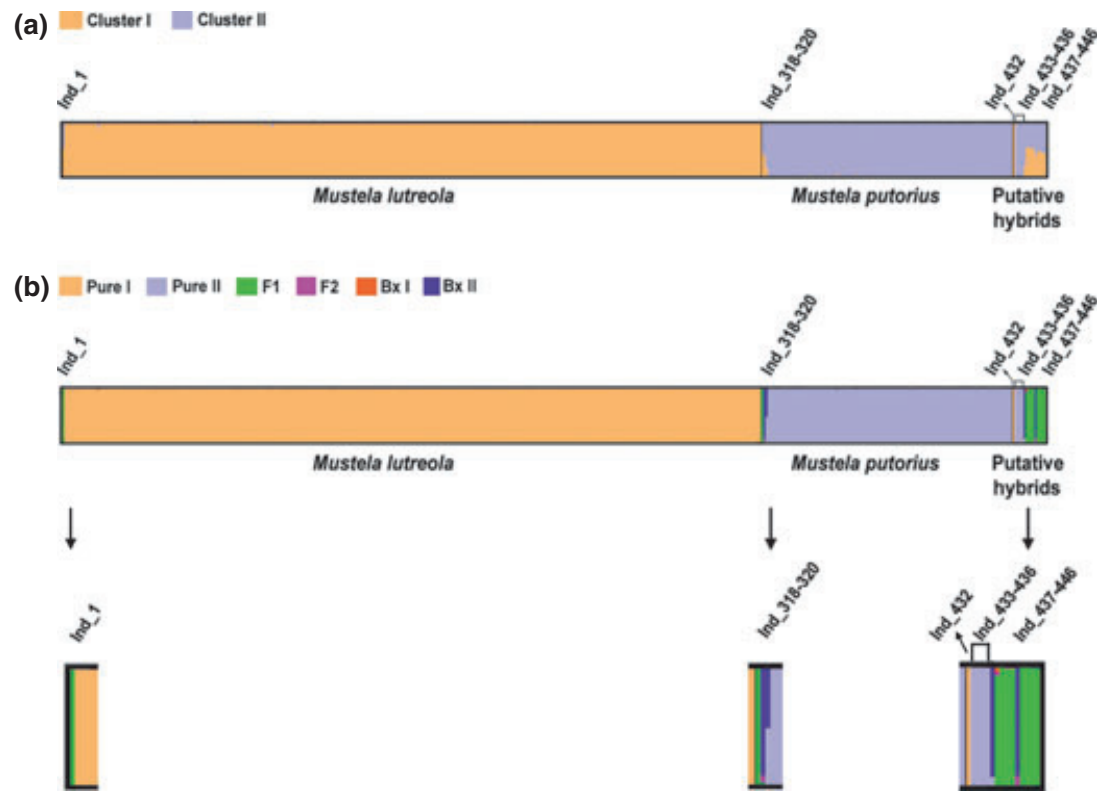

Fig. 3 Detection of hybrids using STRUCTURE (a) and NEWHYBRIDS (b) without prior genetic information. Each individual is represented as a vertical line partitioned into two segments (a) or six coloured segments (b), whose length is proportional to: (a) the individual's estimated membership coefficients and (b) the individual's probability of belonging to the six genotype classes. In (a) the analyses were performed assuming two $(\mathrm{K}=2)$ distinct genetic clusters. In $(b)$ the different genotype categories are: Pure I (European mink), Pure II (polecat), F1, F2, BxI (backcross with European mink) and BxII (backcross with polecat). Individuals are listed in the same order in all analyses. Putative hybrids (Ind 432 to Ind 446) and individuals phenotypically identified as European mink (Ind 1) and polecats (Ind 318 to Ind 320) are specified in both graphs.

$( \pm 0.0037)$ and $0.0081( \pm 0.0046)$ respectively, and of $h$, $0.864( \pm 0.058)$ and $0.935( \pm 0.023)$ respectively.

European mink and polecat clades included 17 and 28 mtDNA haplotypes respectively. Four of them (Mph25, Mph26, Mph27 and Mph28) were newly described for polecat (GenBank accession numbers FJ556593-FJ556597; Fig. 4 and Appendix S1, Supporting information). All individuals phenotypically identified as pure European mink were recovered within clade I. All individuals phenotypically identified as pure polecat were recovered within clade II, except three (Ind 318-320) that clustered within clade I (Fig. 4; Table 2), suggesting European mink ancestry in the maternal line.

Putative hybrids Ind 432 and Ind 437-446 with haplotypes Mlh2 and Mlh11 were included in Clade I, indicating their maternal European mink origin (Fig. 4; Table 2). Haplotype Mlh2 was found only in putative hybrids Ind 445 and Ind 446. The remaining putative hybrid specimens (Ind 433-436) were included in clade II indicating their maternal polecat origin.

\section{$Y$ chromosome sequence diversity and species classification}

Two males phenotypically identified as polecats (Ind 318 and Ind 319) presented Y chromosome haplotype Mph-DDX3Y5 but, as mentioned above, were found to carry European mink mtDNA haplotype Mlh11, which confirmed the hybrid origin of these samples (Table 2). Furthermore, among putative hybrids, the Y chromosome haplotype Mph-DDX3Y5 was reported for eight males (Ind 433-435, with polecat mtDNA; Ind 438, Ind 439 and Ind 443-446, with European mink mtDNA), supporting polecat ancestry in their paternal line, and hybrid origin only for Ind 438, Ind 439 and Ind 443-446 (Table 2). Only one putative hybrid male, Ind 432 (with European mink mtDNA), showed the $\mathrm{Y}$ chromosome haplotype Mlh-DDX3Y5, which indicates the European mink ancestry in the paternal line, and a pure origin for this individual (Table 2). No hybrid males with European mink $\mathrm{Y}$ chromosome and polecat mtDNA sequences were found.

\section{Discussion}

\section{Molecular identification of hybrids}

The genetic analyses performed in this study were based on different molecular markers, and gave consistent results that provided detailed information about hybridization between European mink and polecat. The presence of species-specific microsatellite alleles and loci facilitated pure-bred species distinction, as well as hybrid detection and classification. Notably, they 


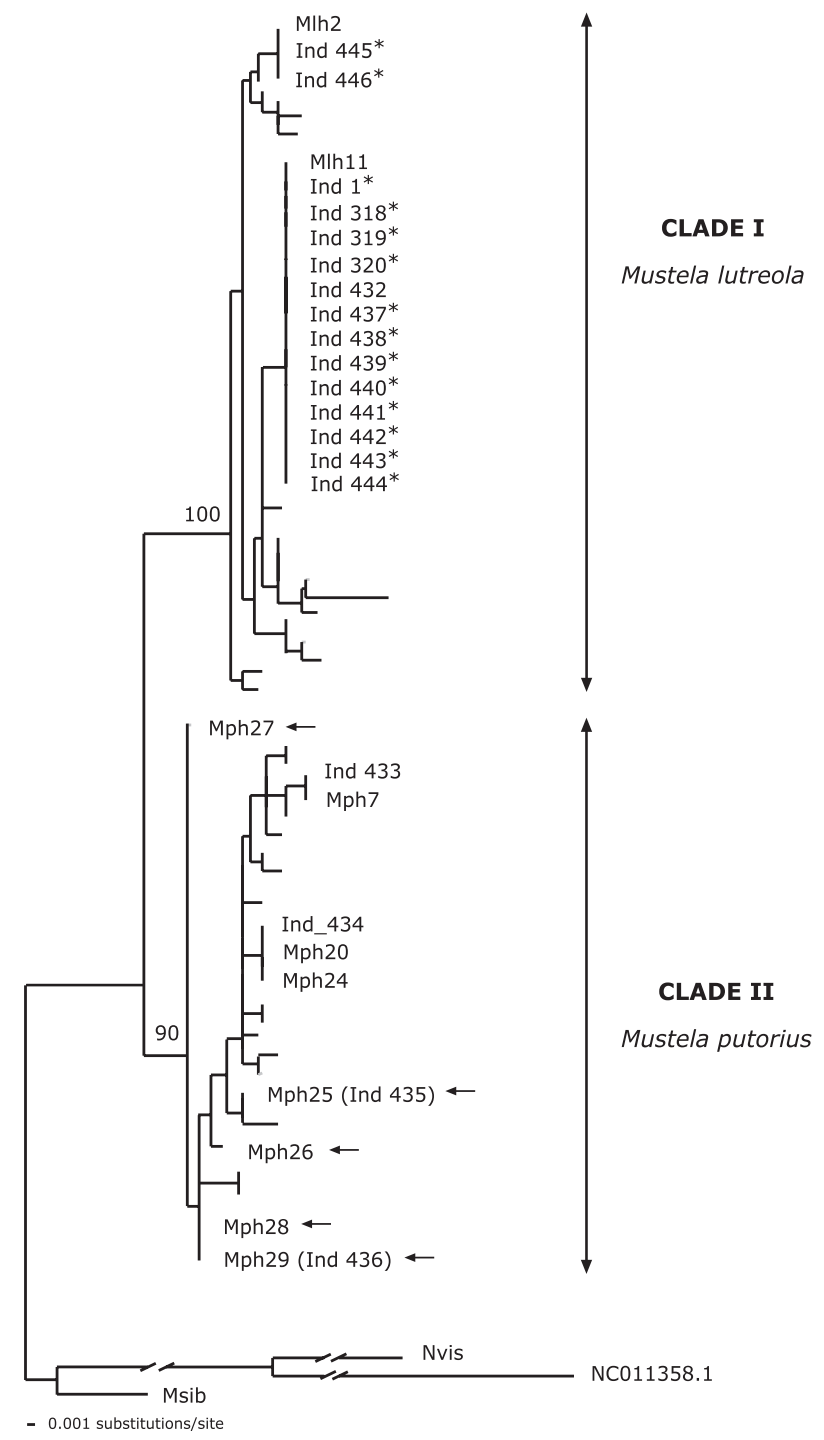

Fig. 4 Phylogenetic relationships of M. lutreola (Clade I) and M. putorius (Clade II) inferred from mtDNA haplotype data using Bayesian inference (BI). Labels indicate putative hybrids (Ind 432 to Ind 446), individuals phenotypically identified as European mink (Ind 1) or polecat (Ind 318 to Ind 320), and European mink (Mlh2, Mlh11) and polecat (Mph7, Mph20 and Mph24 to Mph29) mtDNA haplotypes. Numbers above branches represent Bayesian posterior probabilities. Asterisks ${ }^{*}$ ) identify those confirmed hybrid individuals by genetic analyses whereas arrows $(\leftarrow)$ indicate those new mtDNA haplotypes found in polecat. Outgroups are: Lutra lutra (NC011358.1), Neovison vison (Nvis) and Mustela sibirica (Msib).

enabled the possibility of identifying cryptic phenotypic hybridization. Furthermore, the use of complementary sequence data from both maternal (mtDNA control region) and paternal (Y chromosome DDX3Y5) inheritance markers provided accurate information about the direction of hybridization and additional biological detail on the nature of introgression. Combined use of the three types of genetic markers (autosomal, mtDNA and $\mathrm{Y}$ chromosome) yields best results not achieved by using each marker alone. Thus, the methodological strategy followed in this study should be considered the appropriate choice when characterizing the hybridization process between closely related species (Vila et al. 2003).

A high proportion $(N=432 ; 97 \%)$ of the samples studied were identified as pure European mink or polecat based on mtDNA control region, DDX3Y5 and microsatellite data analyses. In fact, the majority of these samples were originally classified either as pure European mink or polecat based on their phenotype. However, four individuals classified either as pure European mink (Ind 1) or polecat (Ind 318-320) based on phenotype showed admixed microsatellite genotypes, and mtDNA and $Y$ chromosome data corroborated their hybrid ancestry. These cryptic hybrids could correspond with either young animals that have not yet developed the expected admixed phenotypes, or with backcrosses. Conversely, five individuals that were originally considered as putative hybrids were classified as pure European mink (Ind 432) or polecat (Ind 433-436) based on combined genetic evidence. This latter result shows that considerable caution should be taken when identifying unusual phenotypes as hybrids. The remaining putative hybrids were confirmed to have admixed genotypes.

All individuals diagnosed as F1 hybrids based on microsatellite data (Ind 1, Ind 318, Ind 438-441 and Ind 443-446) presented mtDNA sequences that corresponded to European mink haplotypes, suggesting European mink maternal origin. Moreover, all male F1 hybrids showed $\mathrm{Y}$ chromosome sequences that corresponded to polecat haplotype, confirming polecat paternal origin. Hence, the hybridization process occurs in one predominant direction: females of the endangered European mink mate with male polecats. The reciprocal cross was not observed. This asymmetry may be associated with behavioural or sexual isolation between individuals of both mustelid species. In some geographic regions, polecat females have similar or higher body size than European mink males, which may hinder cross-attraction between species and ultimately may prevent courtship or copulation initiation (Coyne \& Allen Orr 2004). The same predominant hybridization direction was observed among polecats and ferrets (Mustela furo; Davison et al. 1999). The bigger-sized male polecats mate with smaller female ferrets, suggesting that behavioural isolating barriers associated to gender body size may not be unusual among mustelids. Nevertheless, other types of prezygotic as well as postzygotic isolating barriers may also occur. 
Levels of hybridization and introgression

Molecular techniques provided reliable information regarding presence and rate of hybridization and introgression phenomena occurring in the populations of the two mustelids. Hybrid proportions reported in this study were generally low because only 3\% $(n=14)$ of the samples showed admixed ancestry. A similar hybrid proportion $(5 \%)$ was detected in grey wolfs of Italy (Verardi et al. 2006). However, levels of introgressive hybridization reported in other mammals were usually higher: $28 \%$ in American mink in Canada (Kidd et al. 2009), 22\% in mongoose lemurs in Madagascar (Pastorini et al. 2009) and $14 \%$ in wild cats in Portugal (Oliveira et al. 2008).

The majority of the genetically detected intermediate individuals corresponded with the first-generation (F1) hybrid class, and only four (Ind 319, Ind 320, Ind 437 and Ind 442) of 446 samples were confirmed as backcross individuals with reliable accuracy. Although the presence of putative hybrid individuals with an intermediate European mink-polecat phenotype has been widely reported previously (Maran et al. 1998; Davison et al. 2000a), backcrosses were only observed in captivity as a result of pure polecats mating with F1 individuals (Maran \& Henttonen 1995). Despite the low number of backcrosses detected, all backcross individuals had European mink mtDNA suggesting that females F1 hybrids are fertile. Conversely, male F1 hybrids seem to be more abundant in proportion but sterile, obeying Haldane's rule (i.e. heterogametic individuals are absent, rare or sterile; Coyne \& Allen Orr 2004). Thus, the results of our study coincide with those obtained previously in captivity where almost all female F1 hybrids were fertile, but only one of 11 male F1 hybrids backcrossed (Ternovsky 1977).

The detected low level of genetic introgression seemed to be also unidirectional because backcrosses were observed to occur only with polecat parental species. Conversely, there was no evidence of genetic introgression of polecat mtDNA or microsatellites into European mink populations. A similar asymmetrical introgression was detected in spotted eagles in Europe, with backcrosses occurring only between F1 hybrids of Aquila clanga/Aquila pomarina towards pure A. pomarina (Väli et al. 2010). One potential explanation to the observed bias takes into account that A. pomarina is a more common species and, therefore, the encounter and mating of F1 hybrids with this parental species would be more feasible and likely (Väli et al. 2010). In our study, the unidirectional introgression pattern detected towards polecat species could also be explained by the relative abundance of this parental species. In this regard, the alternative hypothesis of backcross
(F1 $\times$ pure European mink) could not be discarded as reduced densities of European mink populations would force such backcrossing to remain at low frequencies, which are more difficult to detect. This possibility should be further tested with a larger number of individuals.

\section{Evolutionary and conservation consequences of hybridization}

Hybridization often leads to unviable or infertile F1 individuals. This is the case reported for crosses between European mink and American mink, N. vison, that produced abnormal hybrid embryos, which were reabsorbed at early stages (Ternovsky 1977; Rozhnov 1993). However, the genetic analyses performed in this study support the viability not only of European minkpolecat F1 hybrids but also of backcrosses in the wild, suggesting incomplete reproductive isolation barriers between the two species. The low hybridization and introgression rates detected in this study suggest that these processes are occasional, and might have little contribution to the historical decline of the endangered European mink populations (Maran et al. 1998; Davison et al. 2000b). However, it is important to emphasize that hybridization rates may have increased during the last decades given the important decline of the endangered European mink throughout its distribution (Sidorovich 2001; Lodé et al. 2005). Up to $86 \%(n=12)$ of the genotypically confirmed hybrids were captured in the western European populations, whereas the remaining corresponded to northeastern European populations. All except one hybrid from the western region were detected in the Ebro river region of Spain, suggesting a presence of high hybridization pressure in this area where European mink has decreased significantly in number during the last decades (Palazón et al. 2003; Zabala \& Zuberogoitia 2003). However, these results should be considered with caution as a higher sampling effort was made in this particular region. Thus, hybridization rate estimates could be biased and underestimated outside the Ebro basin.

Hybridization may be increasing in frequency in those sympatric areas where European mink survives in lower densities (Maran et al. 1998; Sidorovich 2001; Lodé et al. 2005) as a forced process that would occur mostly in conditions of scarcity of appropriate mates (European mink males and/or polecat females) between two species with incomplete reproductive barriers. In such cases, hybridization is expected to contribute particularly to the decline of the threatened species and eventually accelerate its extinction. For example, the above-mentioned hybridization in spotted eagles between the vulnerable $A$. clanga and the more common 
A. pomarina is threatening the former in those areas where it survives in low numbers (Väli et al. 2010). Similarly, wild individuals of the critically endangered Fennoscandian arctic fox (Alopex lagopus) were found to hybridize with captive-bred individuals escaped from farms (Norén et al. 2009). The detected genetic ancestry of farm fox in the endangered arctic fox populations of southwestern Norway is considered a severe threat of outbreeding depression through loss of local adaptations to the lemming cycle (Norén et al. 2009). Therefore, if the decline of European mink continues, hybridization could become a substantial threat due to the increasing avoidance of conspecific mates. Moreover, the threat could be even stronger as field monitoring in Spain has revealed instances of hybrid aggressive behaviour against pure European mink (J. López de Luzuriaga, personal observation). Furthermore, given the asymmetry in the hybridization process, and despite the low introgression rate detected so far, a progressive assimilation of European mink by polecats could happen in the future should decline conditions persist (Lodé et al. 2005).

The genetic markers generated in this study, together with newly developed Bayesian procedures, provided highly efficient methods not only for corroborating the pure or admixed ancestry of those specimens with ambiguous phenotype, but also for detecting cryptic hybrids. Furthermore, direction of hybridization and levels of genetic introgression into parental species can be determined. The combination of genetic data with ecological information will be the key for improving not only current European mink conservation programmes but also for developing new management actions for polecats. In order to alleviate hybridization between European mink and polecat species, we suggest that the most effective action is improving European mink population densities by protecting and restoring the habitat of parental species and by restricting other threatening factors, such as hunting or the impact of the American mink. This conservation policy could lead directly to a reduction of the levels of interspecific mating. Furthermore, we propose that management strategies should also contemplate the possibility of hybrid removal from nature, particularly if hybrid aggressive behaviour against European mink is confirmed.

\section{Acknowledgements}

We are most grateful to Gorka Belamendia, Juan Carlos Ceña, Angus Davison, Asunción Gómez, Vladimir Katchanovsky, Andreas Kranz, Sisco Mañas, Santiago Palazón and Madis Podra for providing us with different mustelid samples. This work received partial financial support from three LIFE projects ('Conservación del visón europeo (Mustela lutreola) en "Castilla León" LIFE 00/NAT/E7229, La Rioja' LIFE 00/NAT/E7331 and 'Álava' LIFE 00/NAT/E7335). It was also financed by the Basque Government (Departamento de Educación, Universidad e Investigación del Gobierno Vasco; IT31710) and by the Diputación Foral de Álava (Departamento de Urbanismo y Medio Ambiente). JLL participated in the project 'Proyecto piloto de refuerzo poblacional de visón europeo en los humedales de Salburua, Álava' carried out by the European mink Foundation and financed by Biodiversity Foundation ('Ministerio de Medio Ambiente y Medio Rural y Marino'), Diputación Foral de Álava and the Centre of Environmental Studies ('Centro de Estudios Ambientales-CEA'). MTC was sponsored by a predoctoral fellowship of the Basque Government.

\section{References}

Adams JR, Lucash C, Schutte L, Waits LP (2007) Locating hybrid individuals in the red wolf (Canis rufus) experimental population area using a spatially targeted sampling strategy and faecal DNA genotyping. Molecular Ecology, 16, 18231834.

Allendorf FW, Luikart G (2007) Conservation and the genetics of populations, Blackwell Publishing, Malden, MA.

Allendorf FW, Leary RF, Spruell P, Wenburg JK (2001) The problems with hybrids: setting conservation guidelines. Trends in Ecology \& Evolution, 16, 613-622.

Allendorf FW, Leary RF, Hitt NP, Knudsen KL, Lundquist LL, Spruell P (2004) Intercrosses and the U.S. endangered species act: should hybridized populations be included as westslope cutthroat trout? Conservation Biology, 18, 1203-1213.

Anderson EC, Thompson EA (2002) A model-based method for identifying species hybrids using multilocus genetic data. Genetics, 160, 1217-1229.

Arnold ML (1992) Natural hybridization as an evolutionary process. Annual Review of Ecology and Systematics, 23, 237-261.

Barton NH (2001) The role of hybridization in evolution. Molecular Ecology, 10, 551-568.

Beaumont M, Barratt EM, Gottelli D et al. (2001) Genetic diversity and introgression in the Scottish wildcat. Molecular Ecology, 10, 319-336.

Belkhir K, Borsa P, Chikhi L, Raufaste N, Bonhomme F (2000) GENETIX 4.02, Logiciel sous windows pour la génétique des populations. Laboratoire Génome, Populations, Interactions, Université de Montpellier II, Montpellier, France.

Birks J (1995) Recovery of the European polecat (Mustela putorius) in Britain. Small Carnivore Conservation, 12, 9.

Cabria MT, González EG, Gómez-Moliner BJ, Zardoya R (2007) Microsatellite markers for the endangered European mink (Mustela lutreola) and closely related mustelids. Molecular Ecology Notes, 7, 1185-1188.

Chapuis MP, Estoup A (2007) Microsatellite null alleles and estimation of population differentiation. Molecular Biology and Evolution, 24, 621-631.

Coyne JA, Allen Orr H (2004) Speciation. Sinauer Associates Inc., Sunderland, MA.

Davison A, Birks JDS, Griffiths HI et al. (1999) Hybridization and the phylogenetic relationship between polecats and domestic ferrets in Britain. Biological Conservation, 87, 155-161. 
Davison A, Birks JDS, Maran T et al. (2000a) Conservation implications of hybridisation between polecats, ferrets and European mink (Mustela spp.). In: Mustelids in a Modern World. Management and Conservation Aspects of Small Carnivore: Human Interactions (ed. Griffiths HI), pp. 153-162. Backhuys Publishers, Leiden, The Netherlands.

Davison A, Griffiths HI, Brookes RC et al. (2000b) Mitochondrial DNA and palaeontological evidence for the origins of endangered European mink, Mustela lutreola. Animal Conservation, 3, 345-355.

Dowling TE, Secor CL (1997) The role of hybridization and introgression in the diversification of animals. Annual Review of Ecology and Systematics, 28, 593-619.

Evanno G, Regnaut S, Goudet J (2005) Detecting the number of clusters of individuals using the software STRUCTURE: a simulation study. Molecular Ecology, 14, 2611-2620.

Excoffier L, Laval G, Schneider S (2005) ARLEQUIN ver. 3.0: an integrated software package for population genetics data analysis. Evolutionary Bioinformatics Online, 1, 47-50.

Falush D, Stephens M, Pritchard JK (2003) Inference of population structure using multilocus genotype data: linked loci and correlated allele frequencies. Genetics, 164, 1567-1587.

Falush D, Stephens M, Pritchard JK (2007) Inference of population structure using multilocus genotype data: dominant markers and null alleles. Molecular Ecology Notes, 7, 574-578.

Fernandes M, Maran T, Tikhonov A et al. (2008) Mustela putorius. IUCN 2010. IUCN Red List of Threatened Species, Version 2010.4. http://www.iucnredlist.org.

Fleming MA, Ostrander EA, Cook JA (1999) Microsatellite markers for American mink (Mustela vison) and ermine (Mustela erminea). Molecular Ecology, 8, 1352-1354.

Frankham R, Ballou JD, Briscoe DA (2002) Introduction to Conservation Genetics. Cambrige University Press, UK.

Gaubert P, Taylor PJ, Fernandes CA, Bruford MW, Veron G (2005) Patterns of cryptic hybridization revealed using an integrative approach: a case study on genets (Carnivora, Viverridae, Genetta spp.) from the southern African subregion. Biological Journal of the Linnean Society, 86, 11-33.

Gómez-Moliner BJ, Cabria MT, Rubines J et al. (2004) PCRRFLP identification of mustelid species: European mink (Mustela lutreola), American mink (M. vison) and polecat ( $M$. putorius) by analysis of excremental DNA. Journal of Zoology of London, 262, 311-316.

Goudet J (1995) FSTAT (version 1.2): a computer program to calculate F-statistics. Journal of Heredity, 86, 485-486.

Gow J, Peichel CL, Taylor EB (2006) Contrasting hybridization rates between sympatric three-spined sticklebacks highlight the fragility of reproductive barriers between evolutionarily young species. Molecular Ecology, 15, 739-752.

Guo SW, Thompson EA (1992) Performing the exact test of Hardy-Weinberg proportion for multiple alleles. Biometrics, 48, 361-372.

Hellborg L, Ellegren H (2003) Y chromosome conserved anchored tagged sequences (YCATS) for the analysis of mammalian male-specific DNA. Molecular Ecology, 12, 283-291.

Huelsenbeck JP, Ronquist FR (2001) MRBAYES: Bayesian inference of phylogeny. Bioinformatics, 17, 754-755.

Huelsenbeck JP, Ronquist FR, Nielsen R, Bollback JP (2001) Bayesian inference of phylogeny and its impact on evolutionary biology. Science, 294, 2310-2314.
Kaeuffer R, Reale D, Coltman DW, Pontier D (2007) Detecting population structure using STRUCTURE software: effect of background linkage disequilibrium. Heredity, 99, 374-380.

Kidd AG, Bowman J, Lesbarrères D, Schulte-Hostedde I (2009) Hybridization between escaped domestic and wild American mink (Neovison vison). Molecular Ecology, 18, 11751186.

Kingston JJ, Gwilliam J (2007) Hybridisation between two sympatrically breeding species of fur seal at îles Crozet. Conservation Genetics, 8, 1133-1145.

Lodé T, Guiral G, Peltier D (2005) European mink-polecat hybridization events: hazards from natural process? Journal of Heredity, 96, 89-96.

Lynch JM (1995) Conservation implications of hybridisation between mustelids and their domesticated counterparts: the example of polecats and feral ferrets in Britain. Small Carnivore Conservation, 13, 17-18.

Maran T (2007) Conservation biology of the European mink, Mustela lutreola (Linnaeus 1761): decline and causes of extinction. Tallinn University Dissertations on Natural Sciences 15, Tallinn, Estonia.

Maran T, Henttonen H (1995) Why is the European mink (Mustela lutreola) disappearing - a review of the process and hypotheses. Annales Zoologici Fennici, 32, 47-54.

Maran T, Macdonald DW, Kruuk H, Sidorovich VE, Rozhnov VV (1998) The continuing decline of the European mink Mustela lutreola: evidence for the intraguild aggression hypothesis. In: Behaviour and Ecology of Riparian Mammals (eds Dunstone N, Gorman M), pp. 297-324. Cambridge University Press, Cambridge.

Michaux JR, Libois R, Davison A, Chevret P, Rosoux R (2004) Is the western population of the European mink (Mustela lutreola), a distinct Management Unit for conservation? Biological Conservation, 115, 357-367.

Michaux JR, Hardy OJ, Justy F et al. (2005) Conservation genetics and population history of the threatened European mink Mustela lutreola, with an emphasis on the west European population. Molecular Ecology, 14, 2373-2388.

Nielsen EE, Bach LA, Kotlicki P (2006) HYBRIDLAB (version 1.0): a program for generating simulated hybrids from population samples. Molecular Ecology Notes, 6, 971-973.

Norén K, Kvaloy K, Nyström V et al. (2009) Farmed arctic foxes on the Fennoscandian mountain tundra: implications for conservation. Animal Conservation, 12, 434-444.

Oliveira R, Godinho R, Randi E, Ferrand N, Célio Alves P (2008) Molecular analysis of hybridisation between wild and domestic cat (Felis silvestris) in Portugal: implications for conservation. Conservation Genetics, 9, 1-11.

Palazón SP, Ruiz-Olmo J, Ceña A, Ceña A, Gosálbez J, GómezGayubo A (2003) Trends in distribution of the European mink (Mustela lutreola L., 1761) in Spain: 1950-1999. Mammalia, 67, 473-484.

Pastorini J, Zaramody A, Curtis DJ, Nievergelt CM, Mundy NI (2009) Genetic analysis of hybridization and introgression between wild mongoose and brown lemurs. BMC Evolutionary Biology, 9, 32-44.

Pertoldi C, Breyne P, Cabria MT et al. (2006) Genetic structure of the European polecat (Mustela putorius) and its implication for conservation strategies. Journal of Zoology, 270, 102-115.

Posada D, Crandall KA (1998) MODELTEST: testing the model of DNA substitution. Bioinformatics, 14, 817-818. 
Pritchard JK, Stephens M, Donnelly P (2000) Inference of population structure using multilocus genotype data. Genetics, 155, 945-959.

Raymond M, Rousset F (1995) GENEPOP (version 1.2) population-genetics software for exact tests and ecumenicism. Journal of Heredity, 86, 248-249.

Rhymer JM, Simberloff D (1996) Extinction by hybridization and introgression. Annual Review of Ecology and Systematics, 27, 83-109.

Rice WR (1989) Analyzing tables of statistical tests. Evolution, 43, 223-225.

Ronquist FR, Huelsenbeck JP (2003) MrBayes3: Bayesian phylogenetic inference under mixed models. Bioinformatics, 19, 1572-1574

Rosenberg NA (2004) DISTRUCT: a program for the graphical display of population structure. Molecular Ecology Notes, 4, 137-138.

Rozhnov VV (1993) Extinction of the European mink: ecological catastrophe or a natural process? Lutreola, 1, 10-16.

Schneider S, Roessli D, Excoffier L (2000) ARLEQUIN, Version 2.001: A Software for Population Genetics Data Analysis. Genetics and Biometry Laboratory, University of Geneva, Geneva.

Sidorovich VE (2001) Findings on the ecology of hybrids between the European mink Mustela lutreola and polecat $M$. putorius at the Lovat upper reaches, NE Belarus. Small Carnivore Conservation, 24, 1-5.

Ternovsky DV (1977) Biology of Mustelids (Mustelidae). Nauka Publication, Novosibirsk.

Thompson JD, Gibson TJ, Plewniak F, Jeanmougin J, Higgins DG (1997) The CLUSTAL $x$ windows interface: flexible strategies for multiple sequence alignment aided by quality analysis tools. Nucleic Acids Research, 25, 4876-4882.

Vähä J-P, Primmer CR (2006) Efficiency of model based Bayesian methods for detecting hybrid individuals under different hybridization scenarios and with different number of loci. Molecular Ecology, 15, 63-72.

Väli U, Dombrovski V, Treinys R et al. (2010) Widespread hybridization between the Greater Spotted Eagle Aquila clanga and the Lesser Spotted Eagle Aquila pomarina (Aves: Accipitriformes) in Europe. Biological Journal of the Linnean Society, 100, 725-736.

Valiere N (2002) GIMLET: a computer program for analysing genetic individual identification data. Molecular Ecology Notes, 2, 377-379.

Vallender R, Robertson RJ, Friesen VL, Lovette IJ (2007) Complex hybridization dynamics between golden-winged and blue-winged warblers (Vermivora chrysoptera and Vermivora pinus) revealed by AFLP, microsatellite, intron and mtDNA markers. Molecular Ecology, 16, 2017-2029.

Verardi A, Lucchini V, Randi E (2006) Detecting introgressive hybridization between free-ranging domestic dogs and wild wolves (Canis lupus) by admixture linkage disequilibrium analysis. Molecular Ecology, 15, 2845-2855.

Vila C, Walker C, Sundqvist AK et al. (2003) Combined use of maternal, paternal and bi-parental genetic markers for the identification of wolf-dog hybrids. Heredity, 90, 17-24.

Weir BS, Cockerham CC (1984) Estimation F-statistics for the analysis of population-structure. Evolution, 38, 1358-1370.

Zabala J, Zuberogoitia I (2003) Current and historical distribution of European mink (Mustela lutreola) in Biscay.
Evolution and comments on the results. Small Carnivore Conservation, 28, 4-6.

M.T.C. is interested in the conservation genetics of different European mammal species. She is currently focused on threatened species such as European mink or Pyrenean desman. J.M. is interested in evolutionary aspects of European mammal species with special emphasis in phylogeny and phylogeography. B.J.G. carries out research on the evolution and conservation of gastropods, fishes, amphibians and mammals using molecular biology techniques. D.S., P.F. and J.L. are field researchers interested in the behavioural ecology, biology and conservation of mustelid species and they have been working for a long time on threatened European mink. T.M. is specialised in the biology and conservation of European mink. He is one of the founder member of the European mink Species Committee, included in EEP Programmes, which is focus on the captive breeding and subsequent re-introduction of threatened European mink for its conservation. R.Z. is interested in understanding the evolutionary mechanisms that are involved in the generation of biodiversity. His research is focused on establishing a robust phylogenetic framework for gastropods and for controversial groups of fishes, amphibians, and reptiles (more information at http://zardoyalab.com/index.php).

\section{Data accessibility}

DNA sequences: GenBank accession numbers, FJ556592 (MlhDDX3Y5); FJ556591 (Mph-DDX3Y5); FJ556593-FJ556597 (mtDNA haplotypes: Mlh1-Mlh17, Mustela lutreola; Mph25Mph28, Mustela putorius); FJ589734 (mtDNA haplotype for Mustela sibirica); FJ589735 (mtDNA haplotype for Neovison vison)

Final sequence assembly: DRYAD entry doi: 10.5061/ dryad.8032.

Microsatellite data: DRYAD entry doi: 10.5061/dryad.8032 (microsatellites: MLUT4, MLUT20, MLUT25, MLUT27 MLUT32, MLUT35, MER09, MER22, MER41, MVIS22, MVIS72, MVIS75, MVIS99).

\section{Supporting information}

Additional Supporting Information may be found in the online version of this article.

Appendix S1 Summary of the samples analysed in this study using mitochondrial (European mink $n=19$; polecat $n=44$; putative hybrid $n=15$ ) and $\mathrm{Y}$ chromosome (European mink $n=7$; polecat $n=12$; putative hybrid $n=10$ ) sequences.

Appendix S2 Histograms showing the frequency distributions of alleles of 13 microsatellite loci obtained for Mustela lutreola (orange) and Mustela putorius (purple) species.

Please note: Wiley-Blackwell are not responsible for the content or functionality of any supporting information supplied by the authors. Any queries (other than missing material) should be directed to the corresponding author for the article. 